\title{
Immune Dysfunction in HIV infected stroke patients: Role of low $\mathrm{CD}_{4}$ counts
}

\author{
*1S.A. Balarabe and 2M.M. Watila \\ 1Department of Medicine Usmanu Danfodiyo University Teaching Hospital, Sokoto, Nigeria. \\ 2Department of Medicine University of Maiduguri Teaching Hospital, Maiduguri, Nigeria \\ [Corresponding author: Email sabalarabe3@yahoo.com; : : +2348036350402]
}

\begin{abstract}
Whether or not low $\mathrm{CD}_{4}$ count directly contributes to stroke among HIV infected stroke patients is yet to be elucidated. This study aimed to ascertain the role of low $\mathrm{CD}_{4}$ count in the pathophysiology of stroke in HIV infection. This was a hospital-based, case-control study. Sixty five (65) consecutive stroke patients (36 males and 29 females) aged 20-68 years and sixty five (65) age-and-sex matched controls were enrolled. A structured questionnaire was administered. Neurological examination was performed and computed tomography scan of the brain done. Blood samples were taken for HIV 1\&2 screening using ELISA method. Positive test using two different kits constituted a positive result. $\mathrm{CD}_{4}$ count was determined by western blot method. The mean $\mathrm{CD}_{4}$ count of HIV positive stroke patients $\left(224.92 \mathrm{cells} / \mathrm{cm}^{3}\right)$ is significantly lower $(\mathrm{P}<0.001)$ than that of HIV negative patients $\left(690.67 \mathrm{cells} / \mathrm{cm}^{3}\right)$. Nine out of thirteen $(9 / 13,69 \%)$ HIV positive stroke patients have $\mathrm{CD}_{4}<200 \mathrm{cell} / \mu \mathrm{\mu l}$. In addition to the conventional risk factors for ischemic stroke in HIV-infected patients, immune dysfunction (low $\mathrm{CD}_{4}$ count) is an important and significant modifiable risk factor of ischemic stroke event among HIV infected adult population of Northeastern Nigeria. Consequently, better understanding and awareness of the role of low CD4 count in the pathogenesis of stroke among HIV adults in this environment may provide a roadmap for controlling one of the deleterious non-opportunistic neurologic complication of HIV infection
\end{abstract}

Keywords: $\mathrm{CD}_{4}$ count, HIV, Immune Dysfunction, Stroke

\section{INTRODUCTION}

Infection with HIV causes immune deficiency to a large extent by decreasing the level and function of $\mathrm{CD}_{4} \mathrm{~T}$ lymphocytes. This effect is accompanied by activation of the immune system, leading to a functional immunosuppression and a state of inflammation and coagulation, which in turns increases the risk of nonopportunistic complications such as stroke (Tipping et al., 2007a). HIV-associated immune activation may also occur due to intimal response to transendothelial migration by neurotropic HIV strains causing intracranial vasculopathy (Mazzoni et al., 2000) There are reported cases of intracranial vasculopathy secondary to immunocompromised state with low $\mathrm{CD}_{4}$ counts; typified by intimal hyperplasia, fibrosis, thickened beaded internal elastic lamina and fragmentation (Tipping et al., 2007b).

Subsequently Aneurysmal disease augmented by dynamic vascular remodeling in response to normal pulsatile shear stress, growth factor and cytokines may occur (Krizanac-Bengez et al., 2004). Undercurrent opportunistic infections may contribute to the production of necessary cytokines that drive this process (Tipping et al., 2007a). Additionally, recent Danish study, found that, HIV positive patients have a higher risk for stroke, especially those with severe disease as determined by lower $\mathrm{CD}_{4}$ cell count (Rasmussen. 2011)

\section{METHODOLOGY}

This was a hospital-based, case-control study. The study population consisted of two groups namely: cases; who were patients with stroke presenting to University of Maiduguri Teaching Hospital (UMTH), and controls; who were healthy volunteers living in Maiduguri. Clearance was obtained from the Ethical Committee of the University of Maiduguri Teaching Hospital. One hundred and thirty subjects were enrolled made up of, sixty five consecutive cases and sixty five controls. Criteria for inclusion into the study were; (a) age above sixteen years, (b) Computed tomographic scan evidence of stroke. Previously diagnosed HIV Patients with computed tomographic scan evidence of intracranial lesions other than stroke were excluded.

A standard questionnaire was administered to each study participant after seeking an informed consent. Information including, age, sex, occupational status and level of education, was obtained. Others Included cigarette smoking, alcohol consumption, current use of drugs such as cocaine and amphetamine, and use of oral contraceptives in women. Information about a prior 
physician diagnosis of medical conditions, such as hypertension, diabetes, sickle cell disease, renal failure, congestive cardiac failure, and cardiomyopathy was obtained

All study participants were physically examined by the investigators, and records made of the subject's weight, height, pulse rate, pulse rhythm, blood pressure, cardiac status oral thrush and lymphadenopathy. Results of investigations were recorded. These included a brain CT scan in the case of stroke cases, fasting blood glucose resting ECG and cholesterol level. Blood samples were taken for HIV 1\&2 screening using ELISA method. Positive results were confirmed by double ELISA. $\mathrm{CD}_{4}$ was determined by western blot method

Statistical analysis was done using SPSS version 11. Risk factors for stroke were tested for Odds ratio. Means of two groups were compared using student's ttest while proportions were compared using chi-squire with Yates correction where appropriate. Any $p$-value less than 0.05 was considered significant.

\section{RESULTS}

One hundred and thirty subjects were enrolled in this study (65 consecutive cases and 65 controls). Among the cases $36(55.2 \%)$ were males and twenty-nine 29 $(44.8 \%)$ were females giving a Male: Female ratio of 1.4: 1 . The age range of the patients was between 20 and 68 years. The highest stroke frequency $(30.8 \%)$ occurred in the age group 55-64 years, while the lowest frequency (6.2\%) was observed in the age group 15-24 years. The mean age of the stroke patients was 47.22 SD 13.64 years and controls 42.42 SD 11.14 years (Tables 1 and Figure 1) The mean age of stroke patients with HIV disease $(36.38 \pm 11.37$ years) was significantly $(P<0.001)$ lower than that of the stroke patients without AIDS disease (49.92 \pm 12.87 years). Thirteen $(20 \%)$ out of 65 stroke patients were HIV positive as against three (4.6\%) among controls $p<$ 0.016 .

The mean $\mathrm{CD}_{4}$ count of HIV positive stroke patient was 224.92 cells $/ \mu$, in comparison the mean $\mathrm{CD}_{4}$ count of HIV negative patients $(690.67$ cells/ $\mu$ l) $(P<0.001)$. Nine $(9 / 13,69 \%)$ HIV positive stroke patients have $\mathrm{CD}_{4}$ count of $<200 \mathrm{cells} / \mu \mathrm{l}$ while the remaining four $(4 / 13$, $31 \%$ ) have $\mathrm{CD}_{4}>200$ cells $/ \mu$ l.
Table 1: Age Distribution of Stroke Among AIDS Patients

\begin{tabular}{ccc}
\hline AGE GROUP & FREQUENCY & PERCENTAGE \\
\hline $15-24$ & 4 & $6.2 \%$ \\
$25-34$ & 8 & $12.3 \%$ \\
$34-44$ & 18 & $27.7 \%$ \\
$45-54$ & 7 & $10.8 \%$ \\
$55-64$ & 20 & $30.8 \%$ \\
$65 \geq$ & 8 & $12.3 \%$ \\
\hline TOTAL & 65 & $100 \%$ \\
\hline
\end{tabular}

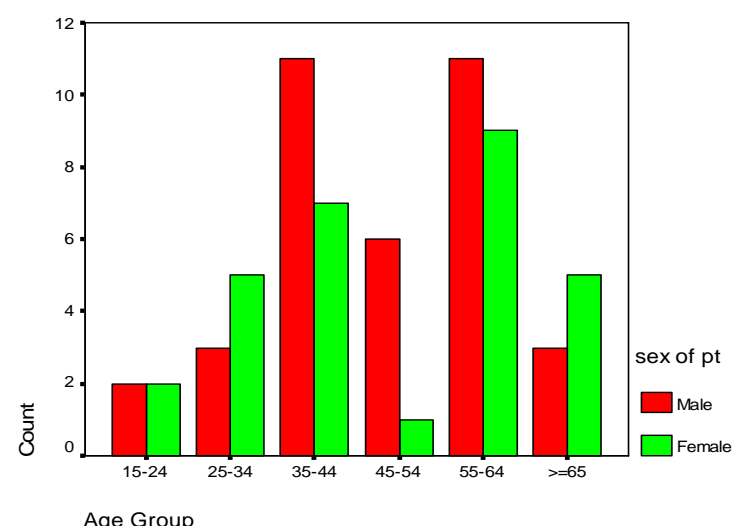

Figure 1: Bar-chart of age and sex distribution of cases

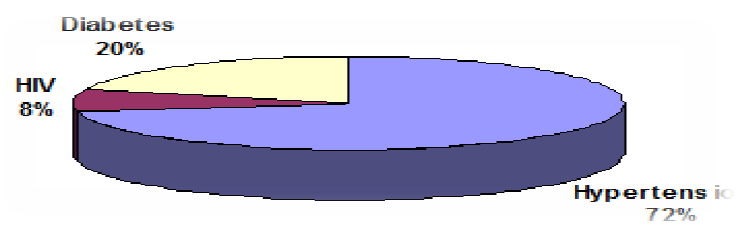

Figure 2: Pie-chart of risk factors for stroke

Table 2: Mean $\mathrm{CD}_{4}$ Count of AIDS Patients and Control.

\begin{tabular}{cc}
\hline HIV status & Mean $\mathrm{CD}_{4}$ count $\left(\mathrm{cells} / \mathrm{cm}^{3}\right)$ \\
\hline HIV+ve & $224.92 \pm 89.37$ \\
HIV-ve & $690.67 \pm 67.26$ \\
\hline$(\mathrm{F}, 11.22 ; \mathrm{P}<.001)$. &
\end{tabular}

\section{DISCUSSION}

The frequency (20\%) of HIV infection among stroke patients in this study is remarkably similar to the $18 \%$ found in a retrospective study among black Africans (Mochan et al., 2003) and 15\% of all strokes in young HIV-infected black Africans in KwaZulu-Natal province of South Africa (Hoffmann et al., 2000). Therefore, findings of this study supported earlier ones that showed that in most parts of Africa, about $25 \%$ of cases 
of stroke occur in young adults and HIV infection is becoming an important contributor (Imam 2002). This high frequency is probably mediated by increased susceptibility of HIV-infected patients to vasculitis and the injury is likely to be due to thrombotic (Cole and Pinto 2004). In addition, various abnormalities predisposing to a hypercoagulable state have also been reported in patients with HIV infection (Imam 2002).

However, the $20 \%$ frequency of HIV infection among stroke patients in this study is higher than 3.4\% frequency of stroke among HIVIAIDS patients reported by Isezuo in an eight-year review of hospitalized patients in Sokoto, north-western Nigeria (Isezuo 2009), $4 \%$ reported in Kinshasa Zaire (Perriens and Mussa 1992) and 5.4\% among Thai young adults (Kiatsak 2002). It is also higher than $0.5-7 \%$ incidence of stroke among HIVIAIDS patients in a clinical study in the United States of America (Ortiz et al., 2007). This may be due to differences in methodology and study areas.

Findings of low CD4+ cells among HIV infected stroke patients in this study is consistent with prior evidence that low CD4+T-cell count may increase the risk of stroke in HIV-infected patients (Hsue et al., 2004; Baker et al., 2007), is also similar to low $\mathrm{CD}_{4}$ count found in (77\%) black South African HIV positive stroke patients (Mochan et al., 2003). Additionally, observational studies in other developing countries have suggested an association between immune dysfunction and stroke based on increased hospital admissions for young immunosuppressed HIV-positive patients with ischemic stroke in the absence of other obvious risk factors of ischemic stroke.(Tipping et al., 2007a; Heikinheimo et al., 2012). This suggests the role of degree of immunosuppression as a determinant of development of neurological manifestation of HIVIAIDS. Furthermore, a Danish study found significant increase risk of total cerebrovascular events in non-IDU HIV- infected individuals with a $C_{4}$ count $<200$ cells $/ \mathrm{ml}$ who had not initiated HAART (Rasmussen LD. 2011) this may give credence to the findings of this study.

In a related development, Chow et al. (2012), showed that HIV was an independent risk factor for ischaemic stroke even after adjustment for usual ischemic stroke risk factors In a comparative study of ischemic stroke incidence in HIV-infected and non-HIV-infected patients in US health care system in 2012. Additionally, CD4 counts $<200$ was found to be associated with increased stroke risk in treatment naive HIV cohort (Chow et al., 2012)

Cole et al., (2004) reported that, $\mathrm{CD}_{4}$ count of < $200 \mathrm{cells} / \mu \mathrm{l}$ is associated with a higher risk for stroke. A study among HIV-infected individuals was shown that, a low $\mathrm{CD}_{4} \mathrm{~T}$-cell count was independently associated with an increased prevalence of carotid lesions (Robert et al., 2008) which is one of the proposed mechanisms of stroke. In addition, earlier study by Mochan et al. (2003), demonstrated association between advanced immunosuppression and opportunistic infections.

\section{CONCLUSION}

In addition to the usual risk factors for ischemic stroke in HIV-infected patients, immune dysfunction (low $\mathrm{CD}_{4}$ count) is an important and significant modifiable risk factor of ischemic stroke event among HIV infected adult population of Northeastern Nigeria. Consequently, better understanding and awareness of the role of low CD4 count in the pathogenesis of stroke among HIV adults in this environment may provide a roadmap for controlling one of the deleterious neurologic complication of HIV infection

\section{REFERENCES}

Baker, J., Peng, G., Rapkin, J., Abrams, D., Silverberg, M. and Cavert, W. (2007). HIV-related Immune Suppression After ART Predicts Risk of Nonopportunistic Diseases: Results From the FIRST study. Conference on Retroviruses and Opportunistic Infections; Boston; 2007. http://www.retroconference.org/2007/Abstracts/ 28667

Chow, F.C., Regan, S., Feske, S., Meigs, J., Grinspoon, S.K. and Triant, V.A. (2012). Comparison of Ischaemic Stroke Incidence in HIVInfected and Non-HIV-infected Patients in a US Health Care System. Journal of Acquired Immune Deficiency Syndrome, 60: 351-58.

Cole, J.W. and Pinto, A.N. (2004). AIDS and Risk of Stroke. Stroke, 25: 51

Ortiz, G., Koch, S. and Romano. J.G. (2007). Mechanism of stroke in HIV-infected Patients. Neurology, 16: 1257-1261.

Heikinheimo, T., Chimbayo, D. and Kumwenda, J.J. (2012). Stroke Outcomes in Malawi, a Country with High Prevalence of HIV: A Prospective Follow-up Study. PLoS One.;7: e33765.

Hoffmann, M., Berger, J.R., Nath, A. and Rayens, M. (2000). Cerebrovascular Disease in Young, HIV- 
Infected, Black Africans in the KwaZulu Natal Province of South Africa. Journal of Neurovirology, 6: 229-236.

Hsue, P.Y., Lo, J.C., Franklin, A., Bolger, A.F., Martin, J.N. and Deeks, S.G. (2004). Progression of Atherosclerosis as Assessed by Carotid Intimamedia Thickness in Patients with HIV Infection. Circulation, 109:1603-1608.

Imam, I. (2002). Strokes: a Review with an African Perspective. Annals of Tropical Medicine and Parasitology, 96: 435-445.

Isezuo, S.A., Obembe, A., Njoku, C.H., Ezunu, A., Maiyaki, S. and Sani, A.Z. (2009). Clinical neuropathy in HIVIAIDS: an Eight-year Review of Hospitalized Patient in Sokoto, Northwestern Nigeria. Tropical Doctor, 39:133-135.

Kiatsak, R. (2002). Etiology of stroke in young Thai Adults. Internal Medicine Journal of Thailand., 18: 42-49.

Krizanac-Bengez, L., Mayberg, M.R. and Janigro, D. (2004). The Cerebral Vasculature as a Therapeutic Target for Neurological Disorders and the Role of Shear Stress in Vasculature Homeostasis and Pathophysiology. Neurological Research., 26: 846-853.

Mazzoni, P., Chiriboga, C.A. and Milla, W.S. (2000). Intracranial Aneurysms in Human Immunodeficiency Virus Infection: Case report and literature review. Pediatric Neurology, 23: 252-255.

Mochan, A. Modi, M, Modi G. (2003). Stroke in Black South African HIV-Positive Patients. A prospective Analysis. Stroke, 34: 10-15.

Perriens, J.H. and Mussa, M. (1992). Neurological Complications of HIV-1 Sero-Positive Internal Medicine Inpatients in Kinshasa, Zaire: Journal of Acquired Immune Deficiency Syndrome., 5(4): 333-340.

Rasmussen, L.D., Engsig, F.N. and Christensen, H. (2011). Risk of Cerebrovascular Events in Persons With and Without HIV: A Danish Nationwide Population-based Cohort Study. AIDS, 25: 1637-1646.

Robert, C.K., Lawrence A.K. and Stephen, J.G. (2008). Low $\mathrm{CD}_{4}+$ T-cells Count as a Major Atherosclerosis Risk Factor in HIV-Infected Women and Men. AIDS, 22: 1615-1624.

Tipping, B., de Villiers, L. and Wainwright, H. (2007a). Stroke in Patients with Human Immunodeficiency Virus Infection. Journal of Neurology Neurosurgery and Psychiatry, 78: 1320-1324.

Tipping, B., de Villiers, S. and Candy, S. (2007b). Stroke Caused by Human Immunodeficiency Virus-Associated Intracranial Large-Vessel Aneurismal Vasculopathy. Archives of Neurology, 63: 1640-1642. 